\title{
Gambaran Pelaksanaan Supervisi Kepala Ruang Terhadap Perawat Pelaksana Dalam Keselamatan Pasien
}

\author{
Maria Hariyati Oktaviani1, Muhamad Rofii ${ }^{2}$
}

1,2 Universitas Diponegoro

\section{Article Info}

\section{Article History: \\ Accepted April 25th 2019}

\section{Key words:}

Supervision; Room leader; patient safety

\section{PENDAHULUAN}

Keselamatan pasien merupakan prioritas yang utama dalam pelayanan kesehatan dan pelayanan keperawatan sekaligus aspek paling penting dari manajemen yang berkualitas. Sasaran keselamatan pasien merupakan syarat untuk diterapkan

\section{Abstract}

The implementation of supervising the head of a room in one hospital in Semarang is not optimal due to the absence of a schedule, assessment instruments, guidance, documentation of the results of supervision, and standard operating procedures (SOP) supervision. Supervision activities are incidental in accordance with needs and have not been implemented in a structured and well-documented manner. The writing of this article aims to describe the perception of the implementation of supervising the head of a room in a hospital in Semarang. This study uses a qualitative descriptive research design. The subjects in this study were all heads of inpatient rooms. The object of this research is the implementation of the supervision of the head of the room according to the SOP and the results of documentation of supervision. The instruments in this study used interview guides, draft sheets, evaluation checklist, supervision of the head of the room and observation sheet for supervision implementation. From the results of the study, it is known that the perception of Lung related to the implementation of supervision is that supervision is still situational, not documented, there is no evaluation and feedback, there is no structured schedule. After socialization shows that there is a change in the implementation of supervision based on SOP before and after the socialization of supervision to the head of the room. Documented supervision results can help the head of the room to see the extent of the ability of staff and can jointly improve capabilities, correct errors in improving the quality of nursing care services. The implementation of supervising the head of space in one of Semarang hospitals needs to be improved especially in terms of post-supervision documentation, development of thematic supervision themes, and structured supervision scheduling.

\footnotetext{
Corresponding author:

Maria Hariyati Oktaviani oktavianinofy@yahoo.com Jurnal Kepemimpinan dan Manajemen Keperawatan, Vol 2 No 1, May 2019 DOI: http://dx.doi.org/10.32584/jkmk.v2i1.165

disemua rumah sakit yang diakreditasi oleh Standar Nasional Akreditasi Rumah Sakit (SNARS). Maksud dan tujuan Sasaran Keselamatan Pasien adalah untuk mendorong rumah sakit agar melakukan perbaikan spesifik dalam keselamatan pasien. Sasaran ini menyoroti bagian-bagian yang bermasalah dalam pelayanan rumah 
sakit dan menjelaskan bukti serta solusi dari konsensus para ahli atas permasalahan ini. Sistem yang baik akan berdampak pada peningkatan mutu pelayanan rumah sakit dan keselamatan pasien (Standar Akreditasi Rumah Sakit (SNARS), 2018).

Data dari beberapa penelitian menyatakan bahwa insiden keselamatan pasien semakin meningkat. Data insiden keselamatan pasien di Minnesota Hospital Woshinton DC meningkat dari 305 laporan pada tahun 2010 menjadi 316 laporan pada 2011 (Stieger, 2012). Hasil penelitian (Purwanto, 2012) juga menyatakan penerapan keselamatan pasien oleh perawat masih belum optimal. Penelitian (Dewi, 2011) di IRNA 1 RSUP Dr Sarjito Yogyakarta menemukan masih banyak perawat di rawat inap kurang baik dalam menerapkan keselamatan pasien yaitu sebesar 48\%.

\begin{tabular}{lcrr} 
Pengelolaan & pelayanan & \multicolumn{2}{r}{ keperawatan } \\
membutuhkan & sistem & manajerial \\
keperawatan & yang & tepat & untuk \\
mengarahkan & seluruh & sumber & daya \\
keperawatan & dalam & menghasilkan
\end{tabular} pelayanan keperawatan yang prima dan berkualitas (Sugiharto, A. S., Keliat, B. A., \& Sri, 2012). Supervisi dan evaluasi merupakan bagian yang penting dalam manajemen serta keseluruhan tanggung jawab pemimpin. Sehingga untuk mengelola asuhan keperawatan dibutuhkan kemampuan supervisi dari seorang manajer keperawatan (Suyanto, 2009). Pemimpin yang paling efektif mempunyai hubungan saling mendukung dengan karyawannya. Bagi perawat di ruang rawat inap, kepala ruangan adalah pemimpin yang dapat menggerakkan perawat untuk dapat melaksanakan asuhan keperawatan dengan baik (Mulyono, H., Hamzah, A., \& Abdullah, 2013).

\section{Penelitian (Mua, 2011) yang} mengemukakan bahwa tidak optimalnya supervisi klinik kepala ruangan harus mendapat perhatian yang serius dari bidang keperawatan, mengingat resiko dan dampak yang dapat timbul berkaitan dengan supervisi klinik kepala ruangan yang tidak optimal yaitu pelayanan keperawatan yang tidak berkualitas. Penelitian (Nainggolan, 2010) mendapatkan bahwa terdapat pengaruh pelaksanaan supervisi kepala ruangan terhadap kinerja perawat pelaksana. Hubungan bermakna strategi supervisi kepala ruang dengan motivasi perawat pelaksana dalam pendokumentasian asuhan keperawatan, yaitu dilihat struktur, keterampilan, dukungan dan keberlanjutan, Sedangkan hasil analisis multivariat faktor yang paling dominan adalah keberlanjutan supervisi setelah dikontrol dengan keterampilan, struktur dan dukungan (Etlidawati, 2012).

Materi supervisi disesuaikan dengan uraian tugas dari masing-masing staf perawat yang disupervisi. Untuk kepala ruang materi supervisi adalah kemampuan manajerial dan kemampuan dalam asuhan keperawatan. Ketua tim disupervisi terkait dengan kemampuan pengelolaan di timnya dan kemampuan asuhan keperawatan. Sedangkan perawat pelaksana disupervisi terkait dengan kemampuan pelayanan dan asuhan keperawatan yang dilaksanakan.

Agar supervisi dapat menjadi alat pembinaan dan tidak menjadi momok bagi staf maka perlu disusun standar penampilan yang diharapkan dari masingmasing staf yang sudah dipahami oleh staf dan ada jadwal yang sudah diketahui dalam supervisi.

Pelaksanaan supervisi kepala ruang di salah satu rumah sakit di Semarang belum optimal dikarenakan belum adanya jadwal, instrumen penilaian, panduan, dokumentasi hasil supervise, dan standar operasional prosedur (SOP) supervisi. Kegiatan supervisi bersifat insidental sesuai dengan kebutuhan dan belum dilaksanakan secara terstruktur dan terdokumentasi dengan baik. Penelitian ini bertujuan untuk mengetahui gambaran pelaksanaan supervisi kepala ruang di salah satu rumah sakit di Semarang. 


\section{METODE}

Penelitian ini menggunakan desain penelitian deskriptif kualitatif, yang bertujuan menggambarkan kepala ruang dalam pelaksanaan supervisi kepada perawat associate. Subjek dalam penelitian ini adalah seluruh kepala ruang rawat inap yang ada disalah satu instalasi rumah sakit di Semarang. Objek penelitian ini mengenai persepsi kepala ruang terkait supervisi dan observasi pelaksanaan supevisi kepala ruang sesuai SOP dan hasil dokumentasi pelaksanaan supervisi. Instrumen dalam penelitian ini menggunakan panduan wawancara, lembar draft ceklist dan lembar observasi evaluasi yang dilakukan Karu berdasarkan SOP yang telah berpedoman pada uraian tugas dan penilaian kinerja kepala ruang dan perawat associate di rumah sakit Semarang.

\section{HASIL}

Gambaran persepsi pelaksanaan supervisi kepala ruang sesuai SOP

Dari hasil penelitian diperoleh tentang pengertian supervisi. Partisipan memandang pengertian supervisi adalah pengarahan, bimbingan, dan evaluasi kinerja perawat, seperti pada pernyataan berikut :

Ehmm supervisi yaa.... Nek gak salah itu seperti proses pengarahan atau bimbingan kepada staf bawahan....... (P1)

Supervisi kepala ruang yaa..... ? kemampuan kita sebagai kepala ruang untuk bagaimana kita mengarahkan, membimbing, bahkan mengevaluasi terkait tindakan asuhan keperawatan untuk meningkatkan kinerja demi keselamatan pasien.... (P2)

Partisipan juga mengungkapkan terkait gambaran mengenai pelaksanaan supervisi yang masih bersifat situasional, tidak terdokumentasi, tidak adanya evaluasi dan feedback, tidak adanya jadwal terstruktur, dapat dilihat pada pernyataan berikut:
Hmm kalau supervisi yang biasa saya terapkan di ruangan saya yaa,, emang masih bersifat situasional jadi supervisi dilakukan jika langsung ditemukan kesalahan pada staf tersebut, jadi tidak adanya jadwal yang pasti, terus saya tidak melakukan dokumentasi sehabis melakukan supervisi, dan tidak juga memberikan feedback atau evaluasi secara terstruktur..... (P1)

Supervisi yang saya terapkan yaa..., langsung saya lakukan supervisi pada perawat yang langsung saya temukan kesalahan saat itu juga. Jadi tidak ada jadwal yang sudah terprogram. Evaluasi yang saya berikan juga masih bersifat umum. Dulu saya melakukan domunetasi, tetapi 1 tahun terakhir ini saya sudah tidak mendokumentasikan hasil supervisi saya... (P2)

Gambaran pelaksanaan supervise kepala ruang sesuai SOP

Tabel 1 Gambaran Pelaksanaan Supervisi Berdasarkan SOP

\begin{tabular}{llll}
\hline & Responden & $\begin{array}{l}\text { Observasi } \\
\text { Supervisi }\end{array}$ & Capaian \\
\hline Pre & Karu Elang 1 & 5 & $50 \%$ \\
& Karu Elang 2 & 5 & $50 \%$ \\
\hline \multirow{2}{*}{ Post } & Karu Elang 1 & 10 & $100 \%$ \\
& Karu Elang 2 & 8 & $80 \%$ \\
\hline
\end{tabular}

Hasil penelitian menunjukan bahwa adanya perubahan pelaksanaan supervise berdasarkan SOP sebelum dan sesudah dilakukan sosialisasi pelaksanaan supervise kepada kepala ruang. Adapun poin-poin terkait dalam SOP yakni; kepala ruang mampu 1) menggali dan mencari tahu masalah, 2) mampu mencari dan menggali kemampuan staf perawat terhadap solusi alternatif pemecahan masalah, 3) mampu memberikan arahan saat supervise, 4) mampu memberikan feedback dan klarifikasi atas hasil supervise, 5) mampu menayakan komitmen staf dalam memperbaiki kesalahan dan berusaha menjadi lebih baik, 6) mampu memberikan reinforcement terhadap pencapaian kemajuan staf perawat dan follow up perbaikan, 7) mampu menetapkan solusi, 8) 
mampu membuat perencanaan tindakan dalam upaya pemecahan masalah, 9) mampu menerapkan gaya komunikasi yang terbuka dan tidak terkesan mengintimidasi staf , 10) mampu menuliskan dokumentasi kegiatan supervisi pada lembar supervisi, mencatat hasil supervisi meliputi tindakan apakah sesuai dengan SPO atau tidak.

\section{PEMBAHASAN}

Upaya yang dilakukan untuk memberikan dukungan pada staf perawat salah satunya melalui kegiatan supervisi. Supervisi yang benar akan meningkatkan kenyamanan dan mengurangi kecemasan sehingga staff dapat melakukan kegiatan dengan adanya dukungan dan bimbingan, hal ini selaras dengan penelitian (Koivu, A. Sarinen, 2012) yang menyatakan bahwa supervisi meningkatkan kenyamanan dalam bekerja.

Undang-Undang Nomor 44 tahun 2009 tentang Rumah Sakit dalam pasal 13 ayat (3) mengamanatkan bahwa "Setiap tenaga kesehatan yang bekerja di rumah sakit harus bekerja sesuai dengan standar profesi, standar pelayanan rumah sakit, standar prosedur operasional yang berlaku, etika profesi, menghormati hak pasien dan mengutamakan keselamatan pasien" (UU No 44, 2009).

Pelayanan keperawatan yang baik, berkualitas dan aman bagi pasien dapat diciptakan melalui supervisi. Menurut RCN 2007 dalam (Sugiharto, A. S., Keliat, B. A., \& Sri, 2012) rumah sakit dan perawat harus memahami supervisi klinis dalam pencapaian hasil akhir (outcome) guna meningkatkan mutu layanan keperawatan melalui sistem evaluasi, kesempatan mempelajari hal-hal baru, meningkatkan retensi staf, efisiensi, dan efektifitas.

Supervisi klinis perlu dilakukan secara terprogram, terjadwal, dan bukan untuk mencari kesalahan atau penyimpangan. Supervisi klinis juga dilakukan terutama memberikan pengarahan dan pembimbingan untuk meningkatkan pemahaman perawat pelaksana dalam menjalankan tugas dan tangung jawabnya dalam memberikan pelayanan. Selain itu proses evaluasi dalam supervisi klinis dilakukan secara continue dan berkesinambungan oleh karena itu perlu adanya metode evaluasi berkala dan continue agar tercapai kualitas pelayanan sesuai dengan visi dan misi rumah sakit.

Hampir semua penanggungjawab ruangan dan ketua tim di rumah sakit Semarang belum mendapatkan pelatihan tentang supervisi klinis keperawatan. Pelatihan dan pengembangan supervisi klinis keperawatan mempunyai pengaruh positif terhadap kinerja perawat. Selain itu pelatihan dan pengembangan supervisi klinis keperawatan merupakan cara untuk memotivasi dan meningkatkan keterampilan kerja. Oleh sebab itu penanggungjawab ruangan dan ketua tim di rumah sakit Semarang perlu diberikan sosialisasi mengenai supervisi keperawatan agar dapat melakukan supervisi dengan baik dan terdapat perbedaan bermakna sebelum dan sesudah dilakukan pelatihan supervisi, dimana supervisi yang dilakukan oleh penanggungjawab ruangan dan atau katim menjadi lebih baik dan optimal setelah mengikuti sosialisasi. (Standar Akreditasi Rumah Sakit (SNARS), 2018) dalam Integrasi Pendidikan Kesehatan dalam Pelayanan Rumah Sakit (IPKP) 5 disebutkan bahwa "pelaksanaan supervisi didokumentasikan dalam log book peserta didik dan staf klinis yang memberikan pendidikan klinis".

Hasil evaluasi didapatkan kepala ruang mengatakan dengan adanya sosialisasi akan pentingya supervise kepala ruang secara terstruktur dan hasil supervise yang didokumentasikan dapat membantu kepala ruang untuk melihat sejauh mana kemampuan staf dan dapat bersama meningkatkan kemampuan, memperbaiki kesalahan dalam meningkatkan mutu pelayanan asuhan keperawatan. 


\section{SIMPULAN}

Supervisor memainkan peran penting untuk mendukung praktik keperawatan berbasis bukti ke dalam praktik keperawatan sehari-hari. Supervisi kepala ruang sebagai upaya untuk menjaga kualitas perawatan, kepatuhan terhadap prosedur dan jaminan pelayanan keperawatan yang semakin baik. Supervisor sebagai pengarah dalam mengembangkan pengetahuan perawat, bukan hanya menilai kemampuan staf tetapi lebih pada upaya memastikan bahwa staf memiliki kemampuan sesuai yang diharapkan.

Tugas dan fungsi supervisor tidak lepas dari tugas dan fungsi manajemen keperawatan itu sendiri, yaitu planning, organizing, actuating dan controlling. Menjadi supervisor adalah sebuah peran yang melekat dan apabila kegiatan tersebut dilaksanakan dengan baik maka akan memberikan dampak positif dan kepuasan, tidak hanya supervisor itu sendiri tetapi bagi perawat ruangan dan pasien.

\section{REFERENSI}

Dewi, S. . (2011). Hubungan fungsi manajemen kepala ruang dan karakteristik perawat dengan penerapan keselamatan pasien dan perawat di IRNA 1 RSUP Dr. Sardjito Yogyakarta (Universitas Indonesia). https://doi.org/http://lontar.ui.ac.id

Etlidawati. (2012). Hubungan strategi supervisi kepala ruang dengan motivasi perawat dalam pelaksanaan pendokumentasi asuhan keperawatan di ruang rawat inap RSUD Pariaman.

Koivu, A. Sarinen, P. . \& K. D. (2012). Clinical supervision promote medical- surgical nurses well-being at work? A quasi experimental 4Year follow-up study. Journal of Nursing Management, 20(3).

Mua, E. . (2011). Pengaruh pelatihan supervisi klinik kepala ruangan terhadap kepuasan kerja dan kinerja perawat pelaksana di ruang rawat inap rumah sakit Woodward Palu (Universitas Indonesia).

https://doi.org/http://lontar.ui.ac.id/file?file =digital $\quad / 20280828 \mathrm{~T} \% 20$ Estelle $\% 20 \mathrm{Lilian} \%$ 20Mua.pdf.

Mulyono, H., Hamzah, A., \& Abdullah, A. A. (2013). Faktor yang berpengaruh terhadap kinerja perawat di rumah sakit tingkat III 16.06.01 Ambon. Jurnal AKK, 2(1), 18-26.

Nainggolan, M. J. (2010). Pengaruh Pelaksanaan Supervisi Kepala Ruangan terhadap Kinerja Perawat Pelaksana di Rumah Sakit Islam Malahayati. USU.

Purwanto. (2012). Pengaruh penggunaan pedoman perencanaan kepala ruang terhadap pelaksanaan keselamatan pasien oleh perawat di RS Haji Jakarta (Universitas Indonesia). https://doi.org/http://lontar.ui.ac.id

Standar Akreditasi Rumah Sakit (SNARS). (2018). NASIONAL AKREDITASI RUMAH SAKIT Edisi 1,.

Stieger, J. (2012). Number of advers health events in Minnesota Hospitals increases slightly in 2011. https://doi.org/http://www.health.state.mn.us /patientsafety/

Sugiharto, A. S., Keliat, B. A., \& Sri, T. (2012). Manajemen keperawatan: aplikasi MPKP di rumah sakit. Jakarta: EGC.

Suyanto. (2009). Mengenal kepemimpinan dan manajemen keperawatan di rumah sakit. Yogyakarta: Mitra Cendikia.

UU No 44. (2009). Undang-undang Republik Indonesia Nomor 44 tahun 2009 tentang Rumah Sakit. 